\title{
SHAPE OPTIMIZATION IN THE DESIGN OF CONCRETE ARCH DAMS - TWO CASE STUDIES
}

\author{
José Paixão $^{1}$, D. Silva Matos ${ }^{1}$ \\ ${ }^{1}$ Direcção Projectos e Investimentos - Barragens. EDP, Gestão da Produção de Energia, S.A. \\ (e-mail: \{josé.paixao,domingossilva.matos\} @edp.pt)
}

\begin{abstract}
The design of arch dams usually involves a prolonged process of successive trial and error redefinitions. The current computer technology however enables to automate this task, in order to achieve the most economic solution overall. In the paper, the implemented optimization method of the geometry of concrete arch dams is presented as well as case studies of its application in the design of two dams under construction in Portugal, namely Baixo Sabor upstream dam, $123 \mathrm{~m}$ high, and Fridão dam, $98 \mathrm{~m}$ high. The dams have to comply with geometric and performance constraints, besides the requirements intrinsic to the construction process and to good engineering practice. These quantities are functions of the design parameters that determine the geometry of the dams, and most of them are nonlinear. The functions with time consuming evaluations (namely those requiring finite element analyses) were estimated by neural networks trained with the results obtained for a set of instances of dam shapes that satisfied the linear constraints and maximized the minimum distance between them. The implementation of global optimization methods (namely direct search and genetic algorithms) proved to be efficient to obtain the feasible dam design with minimum volume of concrete. The case studies illustrate the versatility of this design process.
\end{abstract}

Keywords: Concrete arch dam, Shape optimization, Design criteria.

\section{INTRODUCTION}

The Department of Dams of EDP (Energias de Portugal, S.A.) designed several arch dams along the last decades. The main characteristics of the last projects are summarized in Table 1.

In Figure 1 the crown cantilever shape of the dams listed in Table 1 are shown.

The usual methodology used at EDP in the shape definition of arch dams is outlined below. Preliminary design is usually based on the acquired experience and on the comparison with similar projects. Then, the stability of the crown cantilever section for the dead weight action and the optimum crown curvature for the parabolic arches, in accordance with the valley morphology and the geotechnical conditions, are taken into account. In this stage, analysis using the trial-load method is yet a very valuable way for the first shape adjustment. 
In a second stage, shape definition is refined using finite element models and taking into account the main static and dynamic actions. Subsequently, a shape optimization process is carried out, in order to reduce the concrete dam volume enforcing an appropriate structural behavior.

Table 1. Geometric characteristics of some arch dams recently designed by EDP.

\begin{tabular}{|l|c|c|c|c|c|c|c|}
\cline { 2 - 8 } \multicolumn{1}{c|}{} & \multirow{2}{*}{$\begin{array}{c}\text { Height } \\
(\mathrm{m})\end{array}$} & Crest & Bottom & Crest & $\begin{array}{c}\text { Length }(\mathrm{m}) \\
\text { Basis of } \\
\text { crown } \\
\text { cantilever }\end{array}$ & $\begin{array}{c}\text { Maximum at } \\
\text { arches abut- } \\
\text { ment }\end{array}$ & $\begin{array}{c}\text { Concrete } \\
\text { volume } \\
\left(\mathrm{m}^{3}\right)\end{array}$ \\
\hline Alto Lindoso & 110 & 297 & 60 & 4.0 & 21.0 & 30.1 & 295000 \\
\hline Alqueva & 96 & 348 & 145 & 7.0 & 30.0 & 33.0 & 527000 \\
\hline Foz Coa & 136 & 434 & 80 & 6.0 & 37.7 & 43.4 & 972700 \\
\hline Fridão & 96 & 300 & 32 & 4.5 & 26.7 & 27.6 & 227800 \\
\hline Baixo Sabor & 123 & 505 & 60 & 6.0 & 27.0 & 39.3 & 670000 \\
\hline Foz Tua & 108 & 275 & 68 & 5,0 & 22,0 & 32,0 & 317000 \\
\hline
\end{tabular}

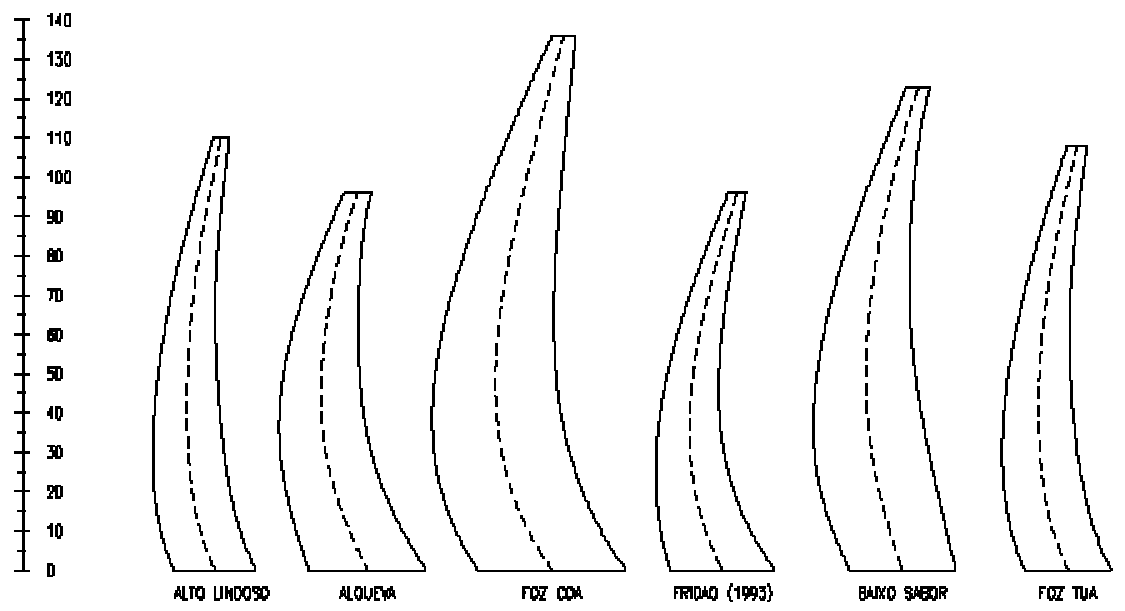

Figure 1. Shape of arch dams crown cantilevers.

After, a final checking of the structural behavior of the dam for all the mandatory scenarios according to Portuguese regulations on dams has to be performed. Furthermore, in accordance with specific conditions of the dam a set of additional studies may be considered as advisable and may also be carried out.

This paper presents a customized method for the optimization of concrete arch dam shapes, which was developed recently at EDP, and was applied to two large dams. The results obtained in tests carried out promoted successive evolutions of the conceptualization of the proposed optimization process of arch dam shapes. Before the appraisal of the performance aspects of the numerical optimization methods relevant to the problem, it is of uppermost importance the proper selection of the most suitable formulation of the design variables and constraints, so that they best achieve the aimed engineering intent. 


\section{METHODOLOGY}

The geometric definition of the arch dams is usually based on a Cartesian referential $O x y z$, where the origin $O$ is located at the closure of the central alignment of the crest; the axis $O x$ and $O y$, horizontals, are respectively tangent and normal to this central alignment, towards the left abutment and downstream, and the axis $O z$ is descendent.

The shapes of the arch dams usually designed by EDP are based on horizontal parabolic arches defined by the following functions (Equation 1 and Figure 2): the crown cantilever $(x=0)$ centerline $a(z)$ and thickness $e_{0}(z)$, the curvature radius of the parabolic arches centerlines at the crown cantilever $p(z)$ and the increasing evolution of the arches thickness from crown cantilever towards the abutments $A(z)$. Polynomial definitions are used for these four shape defining functions, where the depth $z$ measured from the crest level is taken as the independent variable.

$$
\begin{gathered}
y(x, z)=x^{2} /[2 \cdot p(z)]-a(z) \\
e(x, z)=e_{0}(z) \cdot\left[1+A(z) \cdot x^{2}\right] .
\end{gathered}
$$
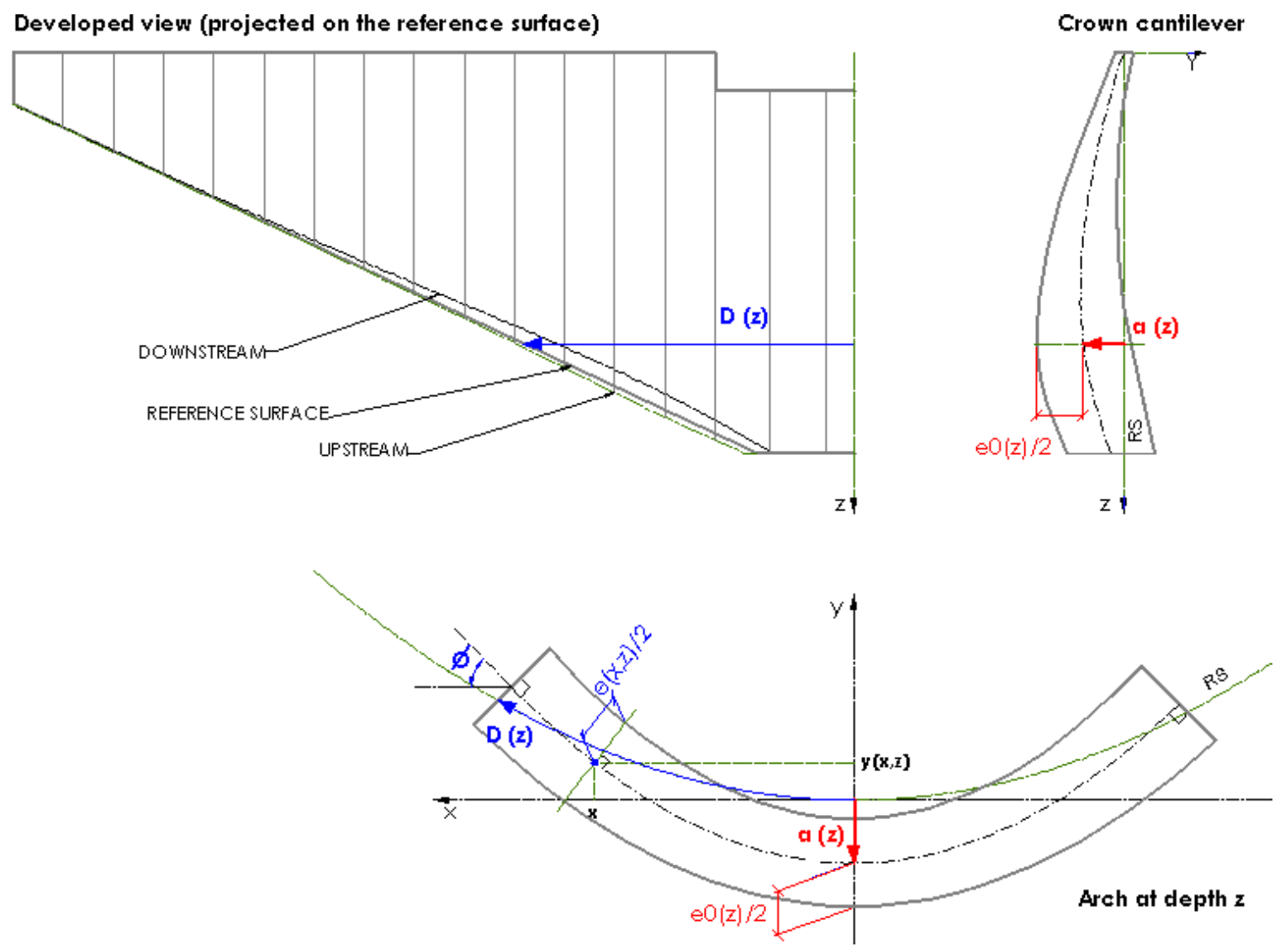

Figure 2. Geometrical definition of the arch dam: shape defining functions.

The numerical study of the geometric definition of an arch dam aims to achieve an appropriate structural behavior with a shape configuration associated to the minimum 
concrete volume, besides the requirements intrinsic to the construction process and to good engineering practice.

The adopted behavior constraints, evaluated from the results of the 3D finite element analysis performed with the Ansys commercial software, were the following ones:

- Higher values of the principal compression and tension stresses of the mean stress state at the faces of the finite elements which model the zones presenting higher stress levels at the upstream and downstream dam faces, including those close to the foundation.

- Ratio between the tangential and the normal components of the global forces transmitted to foundation along the base of each dam block.

These physical quantities, which take into account the strength characteristics of the concrete and the foundation rock mass, assess the safety conditions of the structure with respect to local concrete failures and its overall stability, respectively.

The following geometric requirements which implicitly express some aspects of the good engineering design and of the construction process were cumulatively considered:

- The value of the curvature radius of the parabolic crest axis at the crown, $p(z=0)$, and the crest thickness, $e_{0}(z=0)$, (the crest is assumed to have constant thickness) are prescribed;

- The distance $d_{m}(z)$, from the upstream alignment of the dam insertion on the foundation to the crest axis, as measured in the normal horizontal to this axis, increases with the foundation depth and cannot overtake a prescribed limit value;

- The vertical slope of the faces along the crown cantilever must have a monotonic evolution with the depth, and its value at the crest shall be below $1 / 3 \mathrm{H} / \mathrm{V}$;

- The horizontal thickness in the crown cantilever, $e_{0}(z)$, increases with the depth until two thirds of the dam height and must have also a prescribed limit value;

- The thickness of the arches increases monotonically from the crown to the abutments, and its value at the abutments, $e_{n}(z)$, must be lower than a limit value.

These geometric constraints may be expressed by linear inequality expressions of the quantities $a(z), e_{0}(z), e_{n}(z)$ and $d_{m}(z)$. But, as these two last parameters are nonlinear functions of the four shape defining quantities $p(z), a(z), e_{0}(z)$ and $A(z)$ referred above, they have been chosen, instead of $p(z)$ and $A(z)$, to constitute the definition functions set of the optimization problem. This option decreases the number of nonlinear constraints, and so reduces the number of iterations of the optimization process and contributes to restricts, ad initio, the design domain.

The design variables are the contraction joints grouting temperature and a set of parameters that characterize the above referred definition functions. Several strategies for the characterization of these last parameters were adopted, namely the use of the coefficients of the polynomial definition functions, and the use of the values of these functions at some discrete depths. It was concluded that this last procedure was a better strategy in terms of reproducing the structural behavior, and so reducing the nonlinear evolution of the objective and constraint functions, despite it leads to a greater number of design variables. So each of the four functions of the depth $z$ - namely $a(z), e_{0}(z), e_{n}(z)$ and $d_{m}(z)$ - were characterized through its values at the 10 relative depths $z / h=0.15,0.30,0.45,0.55,0.65,0.75,0.85,0.90$, 
0.95 and 1.00 ( $h$ is the height of the dam) and were linearly interpolated between these depths. These sampling points fill more densely the greater depths, where those functions have pronounced evolutions, which are important for the structural behavior of the dam. These 41 design variables of the optimization problem were normalized in the unitary interval.

In a previous study the thickness and the distance to the vertical reference surface at some discrete control depths along several radial profiles were adopted for the set of design variables. This free-form approach, which intrinsically is less geometrically constrained, requires an algorithm for the interpolation of the geometry of the upstream and downstream dam faces based on those parameters. Although this parameterization provides interesting findings, however the final fitting (by minimization of the sum of square differences) of this interpolated geometry to the referred geometric definition framing may leads to substantial behavior changes, and so it was not used furthermore.

This nonlinear constrained optimization problem requires the structural analysis of numerous dam shape instances inherent to the great number of design variables and to the iterative process.

The evaluation of the performance criteria is based on the results of structural analysis using the finite element method, which requires significant calculation time. These analyses involve the following three main steps: the pre-processing (evaluation of the dam volume and the geometric constraints, mesh generation and characterization of hydrostatic and thermal actions), the structural analysis itself, performed by the Ansys commercial program through scripts in its APDL programming language, and the post-processing (obtaining the stresses in the facings and the resultant forces in sections). The pre and post- processing steps are implemented through several specialized programs developed at EDP in the Fortran language.

To reduce the computer time elapsed, the optimization phase itself relies on model response estimates provided by trained neural networks. This approach also enables to rapidly test several limit values of the nonlinear constraints, which additionally provides information about the pertinence of optional complementary structural features and so supports the conceptualization process of the whole dam-foundation structure. So, the implemented method for arch dam shape optimization consists in the two consecutive main phases presented below, which were successively refined along the tests carried out.

\section{Stage 1 - Training of the neural networks}

This training phase of the neural network is intended to allow the fast prediction of the relevant physical quantities for the instances of the dam (each instance is fully characterized by a set of values of the design variables), thereby avoiding the structural analyses computer time during the successive iterations of the nonlinear optimization process.

For the training of the neural network, a set of instances was previously obtained in a sequential process. In this process, each instance is generated so that it maximizes its minimum distance (Euclidean norm of the differences between the normalized design variables) to the previously obtained instances and satisfies the linear constraints of the optimization problem. This task uses the fminimax function of the Matlab software. 
In the training phase of the neural network, its optimal architecture, namely the number of layers and the number of neurons per layer, was determined in order to maximize the minimum of the correlation coefficient values between the results provided to the neural networks and the corresponding predictions given by these networks, in each of the training, validation and testing random subdivisions of the supplied set of instances. Within this framework customizations of the Neural Networks module of the Matlab software were developed.

\section{Stage 2 - Optimization of the shapes of the dam}

This phase is intended to minimize the volume of concrete dam, which is also a nonlinear function of the design variables.

In order to search the comprehensive global minimum value, the heuristic optimization methods implemented in the Global Optimization module of Matlab software were used, namely genetic algorithms and direct search method, which look for different basins of attraction in order to not become restricted to local minima.

Briefly, in the first method the algorithm generates an initial trial set of instances which leads to a new set, by permutation and random mutation of the instances design variables. In the direct search method, the algorithm starts with the comparison of the performance of an initial instance provided by the user with a limited number of instances in its vicinity, called mesh. When one of these last instances enhances the performance of the central starting instance, it is selected as the initial instance of a subsequent similar process, but with a doubled mesh length. Otherwise, the algorithm reduces in one half the mesh length and redoes the comparison. These processes are repeated successively until some stopping criteria is satisfied, which can correspond to the convergence of the solution.

In the analyzed problem the latter method found always a convergent solution (unlike the former method), and required fewer number of calculations of the objective function and of the nonlinear constraints.

\section{CASE STUDIES}

The previously described customized shape optimization methodology was applied, in an experimental context, to two large arch dams as following described. It can be pointed out that a simpler shape optimization process had already been carried out by EDP for these dams during their design stage.

\subsection{Baixo Sabor upstream dam}

The Baixo Sabor Hydroelectric Project is situated in the north-east of Portugal in the lower branch of the Sabor River which is a tributary of the right bank of the Douro River. According to the EDP design in 2005, this Project comprises the construction of two dams, 
the upstream and the downstream one, located about $12.6 \mathrm{~km}$ and $3.3 \mathrm{~km}$ far from the mouth of the Sabor River, respectively. Reversible units will be installed in the powerhouses associated to each dam in order to enable the water pumping from the upper branch of the Douro River to the large reservoir of the upstream dam.

The designed upstream arch dam is a $123 \mathrm{~m}$ high structure, with a total crest length of $505 \mathrm{~m}$ and a total concrete volume of $670000 \mathrm{~m}^{3}$ [1]. For the full storage level located at elevation 234 m.a.s.l. the reservoir capacity is 1095 million cubic meters. A controlled surface spillway is located in the central part of the dam crest with a discharge capacity of $5000 \mathrm{~m}^{3} / \mathrm{s}$. It has four spans ( $16 \mathrm{~m}$ wide and $12.25 \mathrm{~m} \mathrm{high}$ ) controlled by radial gates and is provided of a downstream plunge pool. The underground power house is located in the right bank and has two 81 MW turbine-pumps. Figure 3 shows a preview of the scheme.

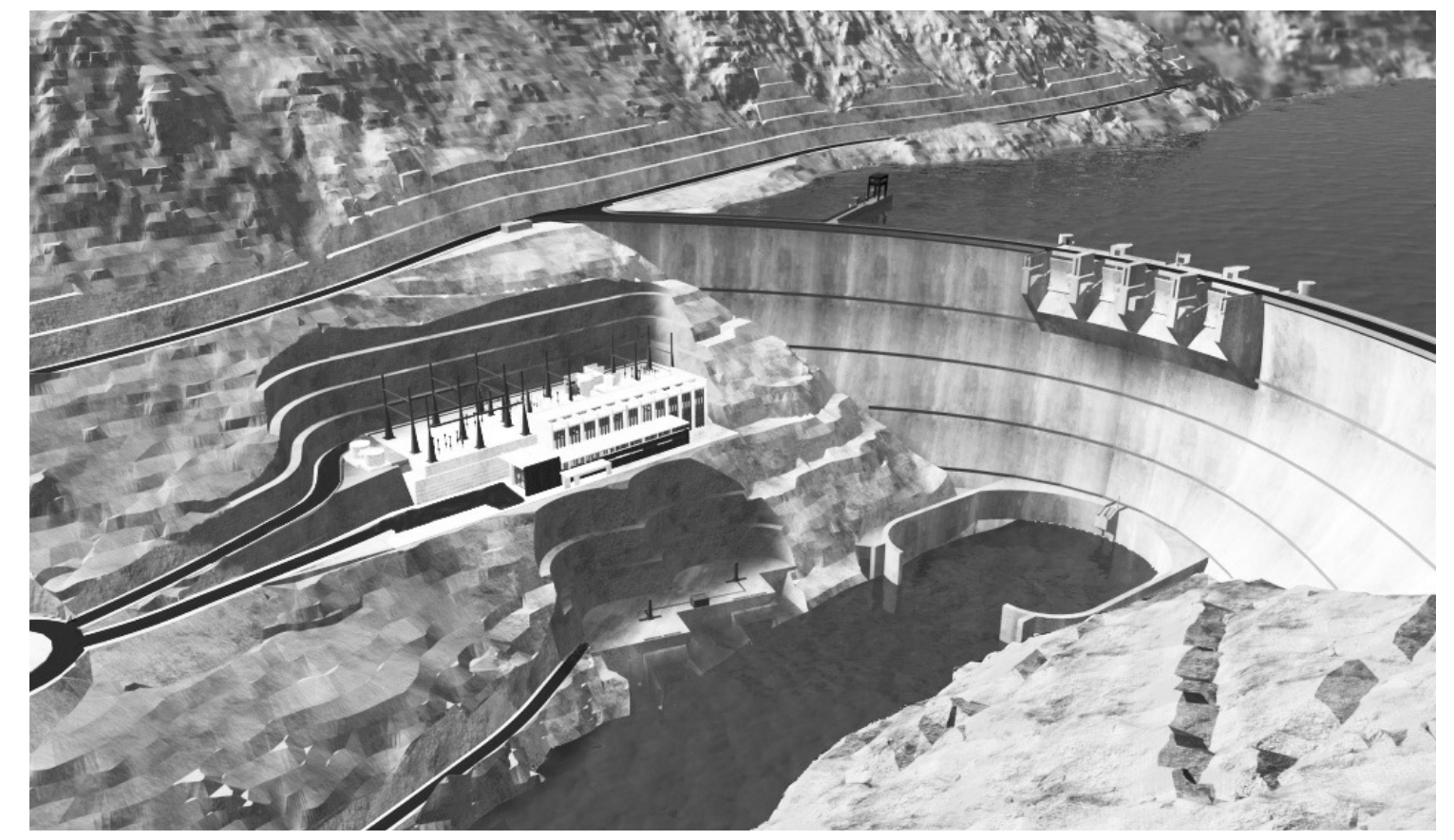

Figure 3. Preview of the the Baixo Sabor upstream dam.

As referred above, the verification of the satisfaction of the performance criteria is based on the results of structural analysis by finite element method of the dam-foundation structure. The adopted finite element mesh model of the dam body and the adjacent foundation zone was composed of 2276 three-dimensional hexahedral finite elements, each with 8 nodes, and 3936 nodes (Figure 4). Four elements were set along the thickness of the dam. 

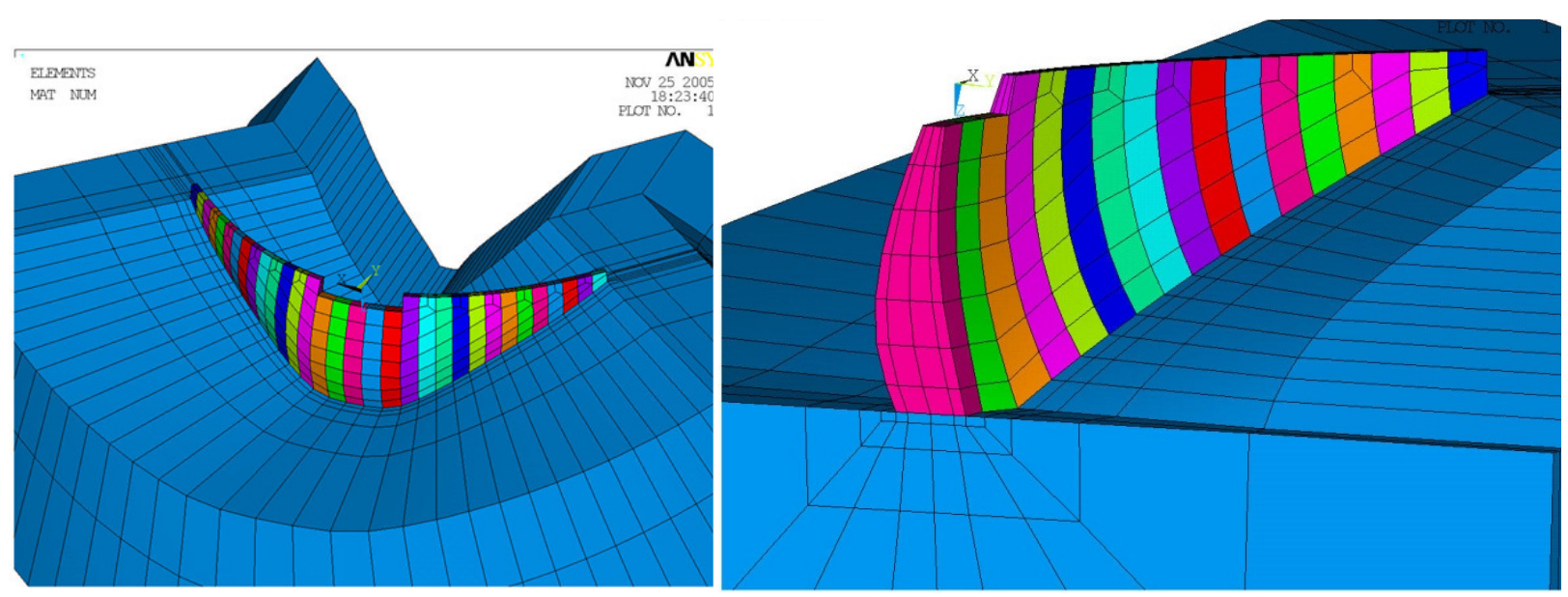

Figure 4. Finite element mesh of the Baixo Sabor upstream dam.

The relevant load combinations, considered according to the Portuguese Regulation requirements, comprise the dead weight of the independent dam blocks along construction $(\gamma$ $\left.=24 \mathrm{kN} / \mathrm{m}^{3}\right)$, the hydrostatic pressure $\left(\gamma=10 \mathrm{kN} / \mathrm{m}^{3}\right)$ at the upstream face for characteristic water table levels of the exploration of the reservoir, the extreme fields of the seasonal variations of temperature in the structure, with respect to the reference field occurring at the date of the contraction joints grouting, and the basis design (BDE) and maximum design (MDE) earthquakes.

The concrete and foundation mass were considered as isotropic, linear elastic materials with the values $\mathrm{E}=20 \mathrm{GPa}, v=0.2$ and $\alpha=10^{-5}{ }^{\circ} \mathrm{C}^{-1}$ for the mechanical proprieties.

The limit values of 5.5 and 1.0 $\mathrm{MPa}$ for the compression and tensile stresses, respectively, were considered in the following loading scenarios: construction phase and reservoir filled up to the normal water level. The corresponding values for the scenario of empty reservoir in the summer period were 7.0 and 1.5 MPa.

The limit values of 0.80 and 0.95 were adopted for the ratio between the tangential and normal forces at the base of each dam block for the scenario of reservoir filled up to the normal water level, respectively with and without winter thermal action, and having in account the uplift pressures.

The structural behavior of the dam designed in the project phase is nearly symmetrical with respect to the crown cantilever, and agrees in general terms with the above limits prescribed in the optimization process. It is pointed out that for several load combinations the extreme values of the prescribed stresses occur in vast zones, showing a good exploitation of the structural material.

These aspects are illustrated in Figure 5 which shows the principal stresses at the upstream and downstream faces, for the scenario of the reservoir filled up to the normal water level without thermal action (0.9 MPa tensile and 5.5 MPa compressive stresses along the insertion of the upstream and downstream faces in the foundation, respectively). The raise of the compression arch stresses (with values 4.7 MPa upstream and 4.1 MPa downstream) just below the spillway opening in the central zone of highest arches is noticeable.

The evaluated behavior for the several scenarios comprising the BDE seismic action, 
which was defined by a response spectra based in the Portuguese Regulation and a $0.084 \mathrm{~g}$ peak ground acceleration (return period of 949 years), is completely suitable presenting maximal values of 1.7 MPa for tensile stresses and of 7.0 MPa for compressive stresses.

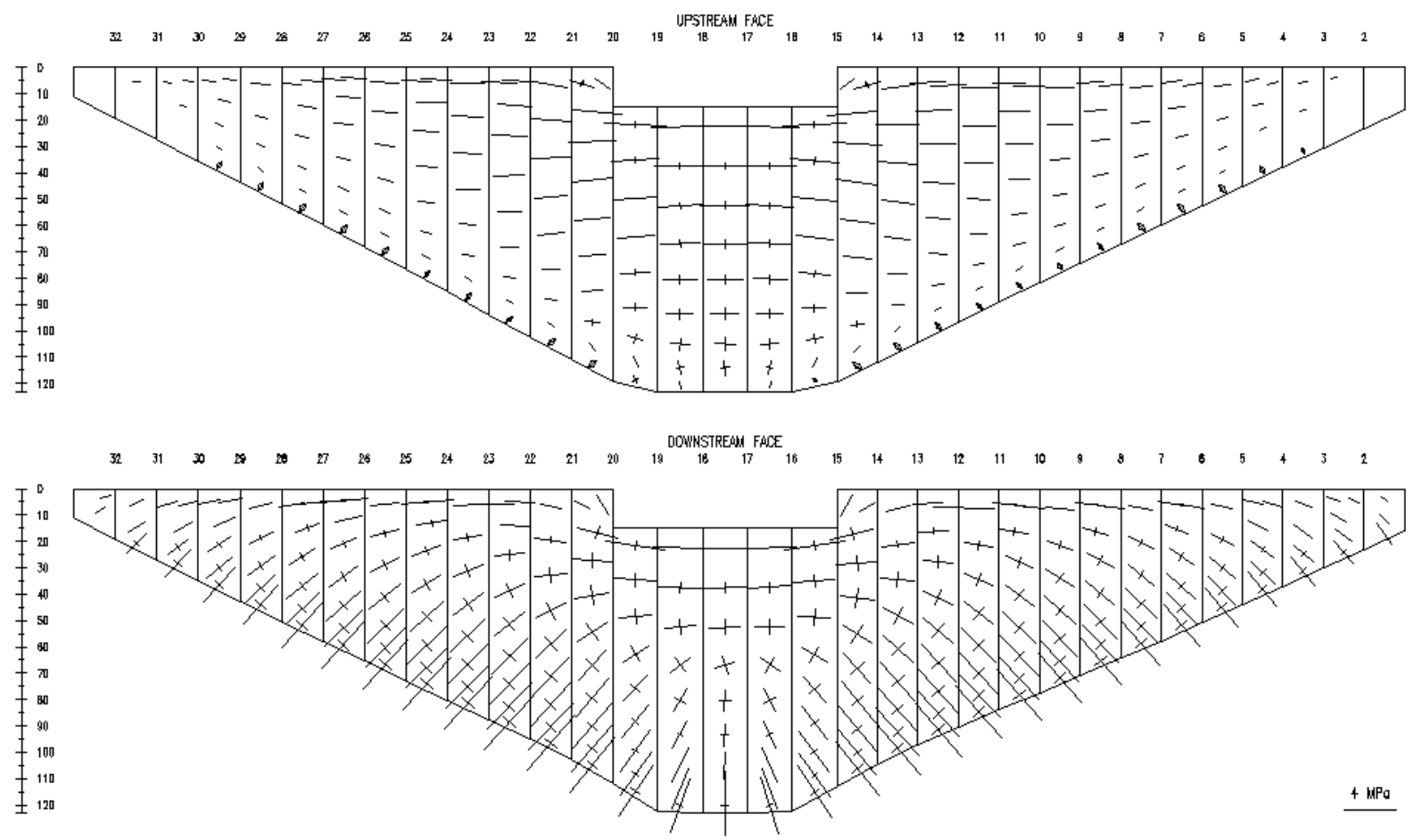

Figure 5. Principal stresses for dead weight and hydrostatic pressure on the $\mathrm{u} / \mathrm{s}$ and $\mathrm{d} / \mathrm{s}$ faces of the Baixo Sabor upstream dam.

The vertical cross sections shown in the Figure 6 illustrate the dam shapes obtained directly by the experimental application to this dam of the developed shape optimization methodology. The obtained shapes require some adjustments typical of these optimization processes, which are easy to implement.

The concrete volume of this optimized solution is about $95 \%$ of that in the project. However, this solution would have to be assessed also for the failure scenarios, which are evaluated by nonlinear analysis, as well as in terms of some qualitative criteria of good engineering practice which are numerically hard to implement.

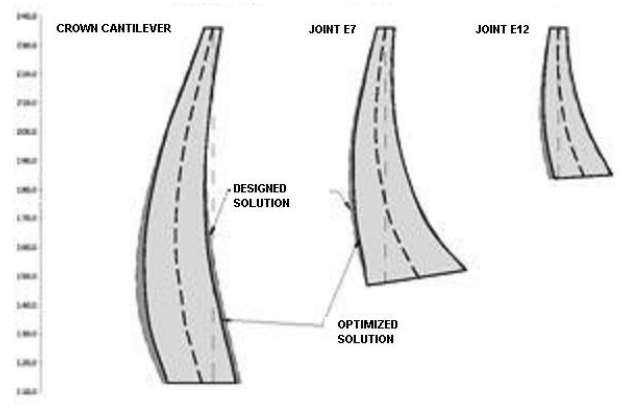

Figure 6. Vertical cross sections of the Baixo Sabor upstream dam, before and after the shape optimization process. 


\subsection{Fridão dam}

The concession of the Fridão Hydroelectric Project was also awarded by EDP Energias de Portugal S.A. in the frame of the Portuguese "National Program of Dams with High Hydroelectric Potential" and its construction will start in the second half of 2012. It is located in the northwest region of Portugal, in the middle reach of Tâmega River, one of the most important right bank tributaries of Douro River. The main dam is a concrete arch type with a maximum height of $98 \mathrm{~m}$, a crest length of $300 \mathrm{~m}$ and a total concrete volume of $251500 \mathrm{~m}^{3}$ (Figure 7) [2]. The rock foundation is mainly composed of hornefels and aplitepegmatites. A gated surface free fall spillway is incorporated over the central part of the dam body, with a design discharge capacity of $4000 \mathrm{~m}^{3} / \mathrm{s}$, as well as a bottom outlet designed for a $250 \mathrm{~m}^{3} / \mathrm{s}$ flow.

The underground hydraulic circuit, in the right bank is completely independent of the main dam, has a total length of about $380 \mathrm{~m}$ and a current concrete lined cross section with $10.5 \mathrm{~m}$ diameter. The shaft powerhouse is equipped with one non-reversible Francis turbine designed for a nominal $350 \mathrm{~m}^{3} / \mathrm{s}$ flow. The erection and command building and the compact switchyard are located in the access powerhouse surface platform, excavated in the hillside. The project also includes a downstream concrete gravity dam about $30 \mathrm{~m}$ high, located $4.2 \mathrm{~km}$ from the main dam.
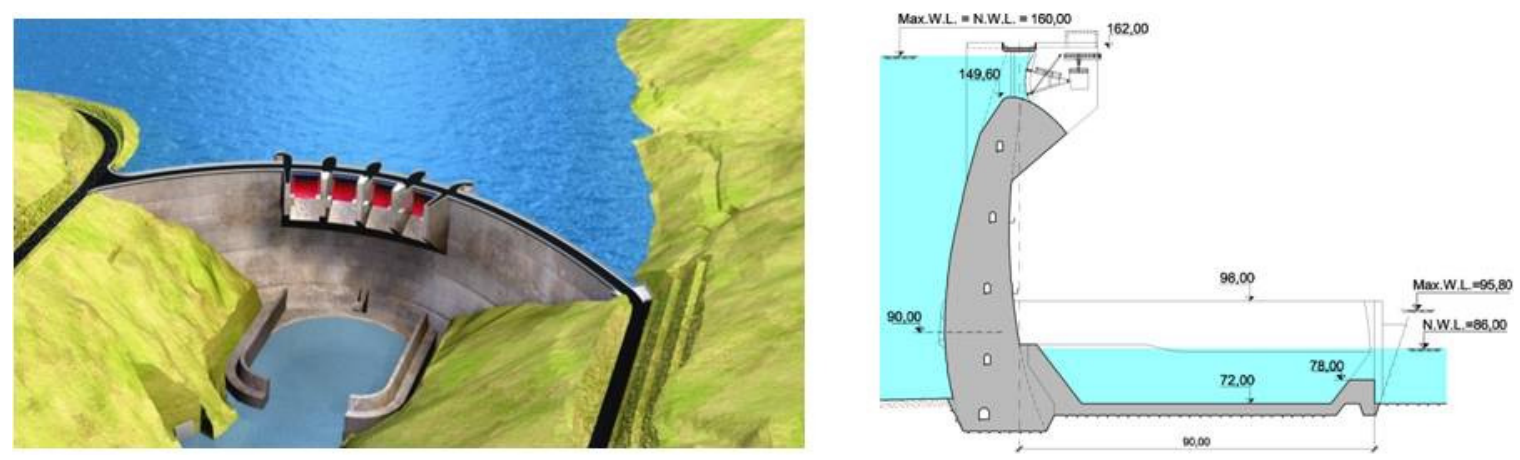

Figure 7. Fridão Hydroelectric Project. Preview and cross section of the dam.

Baixo Sabor upstream dam and the main dam of Fridão Project are dissimilar structures. Fridão dam has a lower height dam than Baixo Sabor dam (98 m against $123 \mathrm{~m}$ ) and lies in a narrower valley, so its crest length is smaller (300 m against $505 \mathrm{~m}$ ).

The vertical cross sections and the foundation plan shown in Figures 8 e 9 illustrate the dam shapes obtained directly by the experimental application to Fridão dam of the shape optimization methodology presented in this paper. It can be pointed out that the abutment thickness of the optimal solution is significantly higher at a depth of about $2 / 3$ of the height, and the curvature radius of the deeper horizontal arch is lower. For Fridão dam the concrete volume reduction is about $2 \%$ with respect to the solution adopted in the project (note that this project solution had been obtained through a simpler optimization process). 


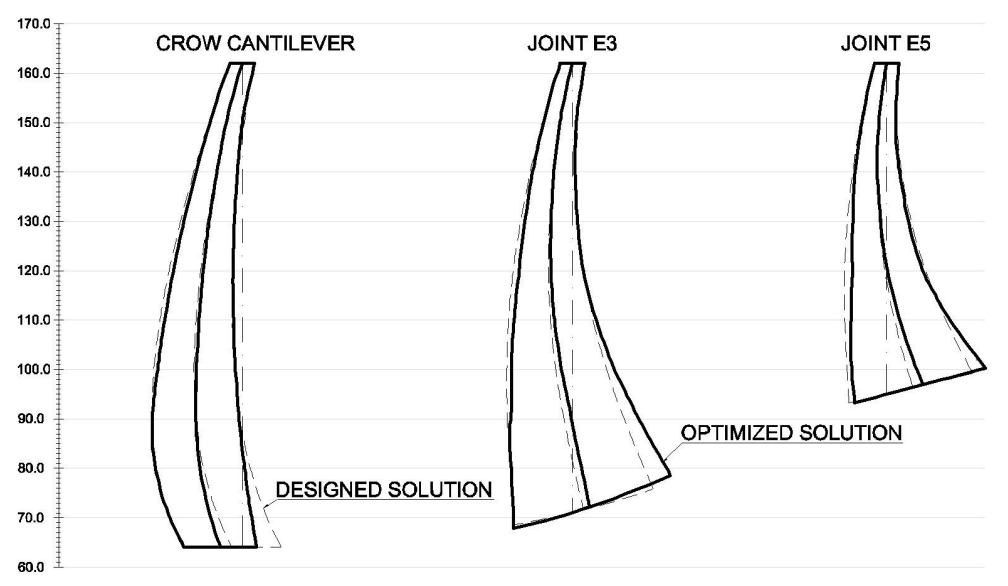

Figure 8. Vertical cross sections of the Fridão upstream dam, before and after the shape optimization process.

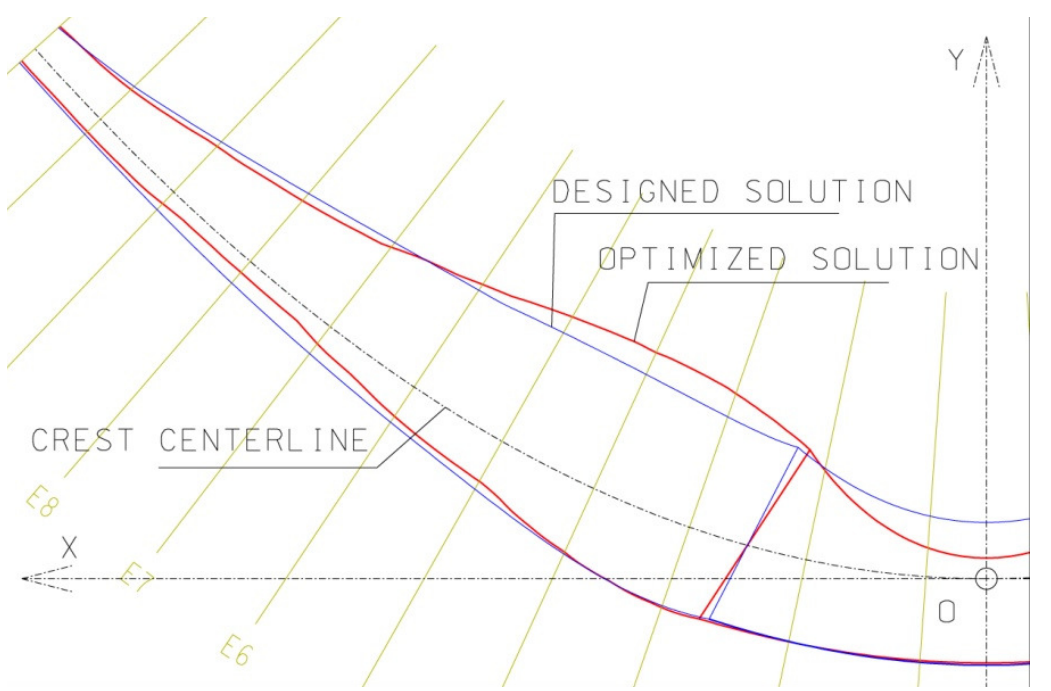

Figure 9. Plan of the concrete-rock contact surface of Fridão dam, before and after the shape optimization process.

These two case studies revealed that the major limitation of the implemented approach is the imprecision of the predictions foreseen by the neural networks in the vicinity of the optimum solution, although high values of the correlation coefficients between data and results were attained during its training step. This implies that the sampled instances used in the training of neural networks are not sufficient to satisfactorily characterize the responses evolution along the domain of the design variables. To obviate this, it is intended to 
implement an evolutionary parameterization of the neural networks, which can proceed to a judicious refinement (based on concepts of Bayesian statistics) of the instances set used in its training, in order to increase the design space knowledge in potentially interesting areas as well as in areas where there is little information.

\section{CONCLUDING REMARKS}

A customized method for global optimization of the concrete arch dam shapes is presented for the minimization of the dam concrete volume, while ensuring an appropriate structural behavior, besides the requirements intrinsic to the construction process and to good engineering practice. It is pointed out the relevance of the judicious selection of the numerous design variables of this nonlinear constrained optimization problem, in order to reduce the nonlinear behavior of some geometric and performance constraints. The conceived approach implements heuristic methods based in neural netwoks metamodels of the structure behavior. For this purpose a sampling method of the training set was developed. The experimental application of the devised approach to the two large arch dams proved to be a good tool for the dam shape optimization. Lastly it is suggested to enhance the method the implementation of an evolutionary parameterization process of the neural networks in order to improve their accuracy.

\section{REFERENCES}

[1] EDP, Electricidade de Portugal, S.A.. 'Aproveitamento Hidroeléctrico do Baixo Sabor. Projecto. Escalão de montante. Volume I. Tomo A. Barragem’ 2005 (in Portuguese).

[2] EDP, Gestão da Produção de Energia, S. A.. 'Aproveitamento Hidroeléctrico de Fridão. Projecto' 2011 (in Portuguese). 